\title{
COMBINE - a vision
}


Is the mosaic of standards complete?

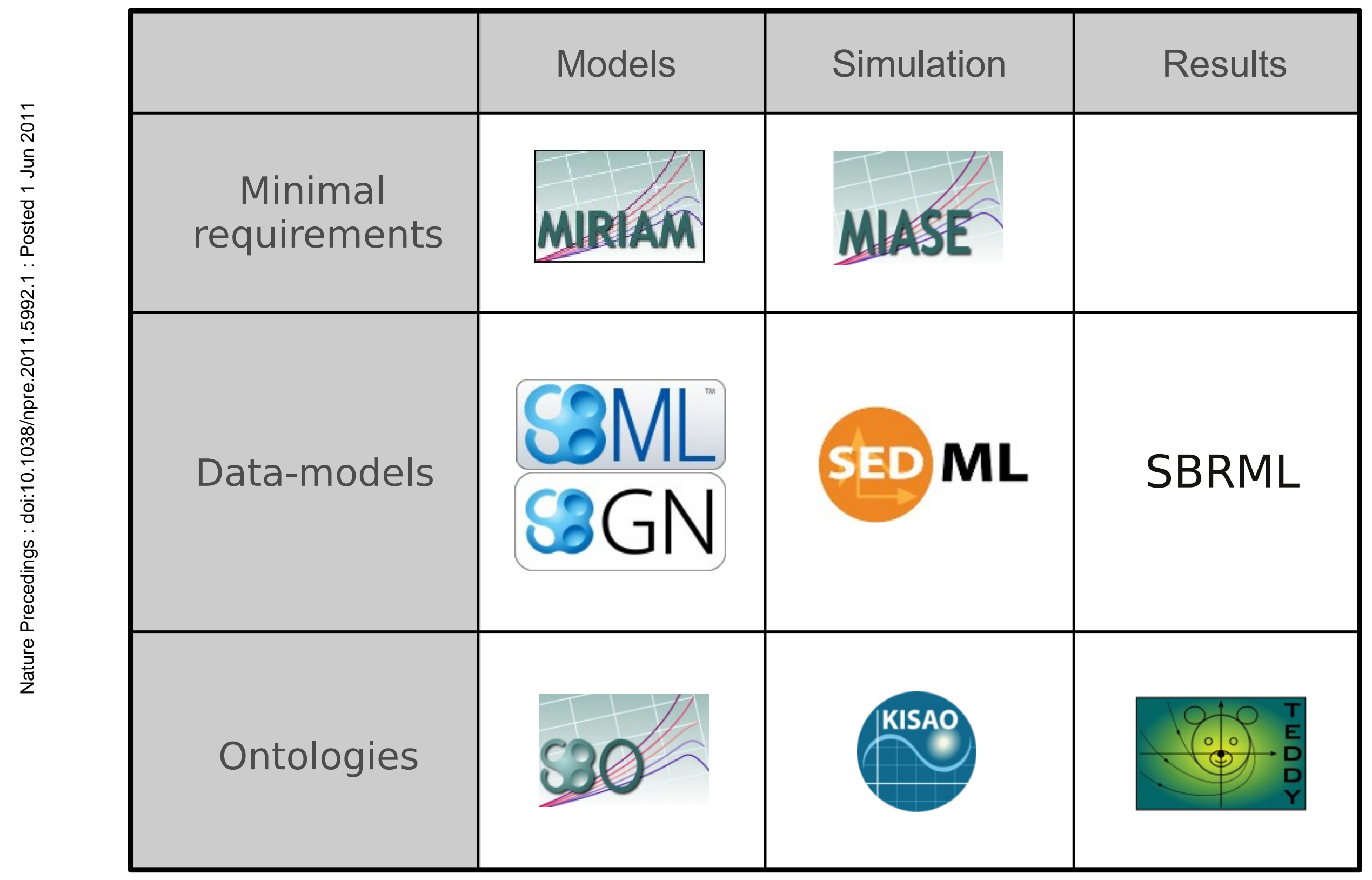




\section{Disentangling the level of discourse}

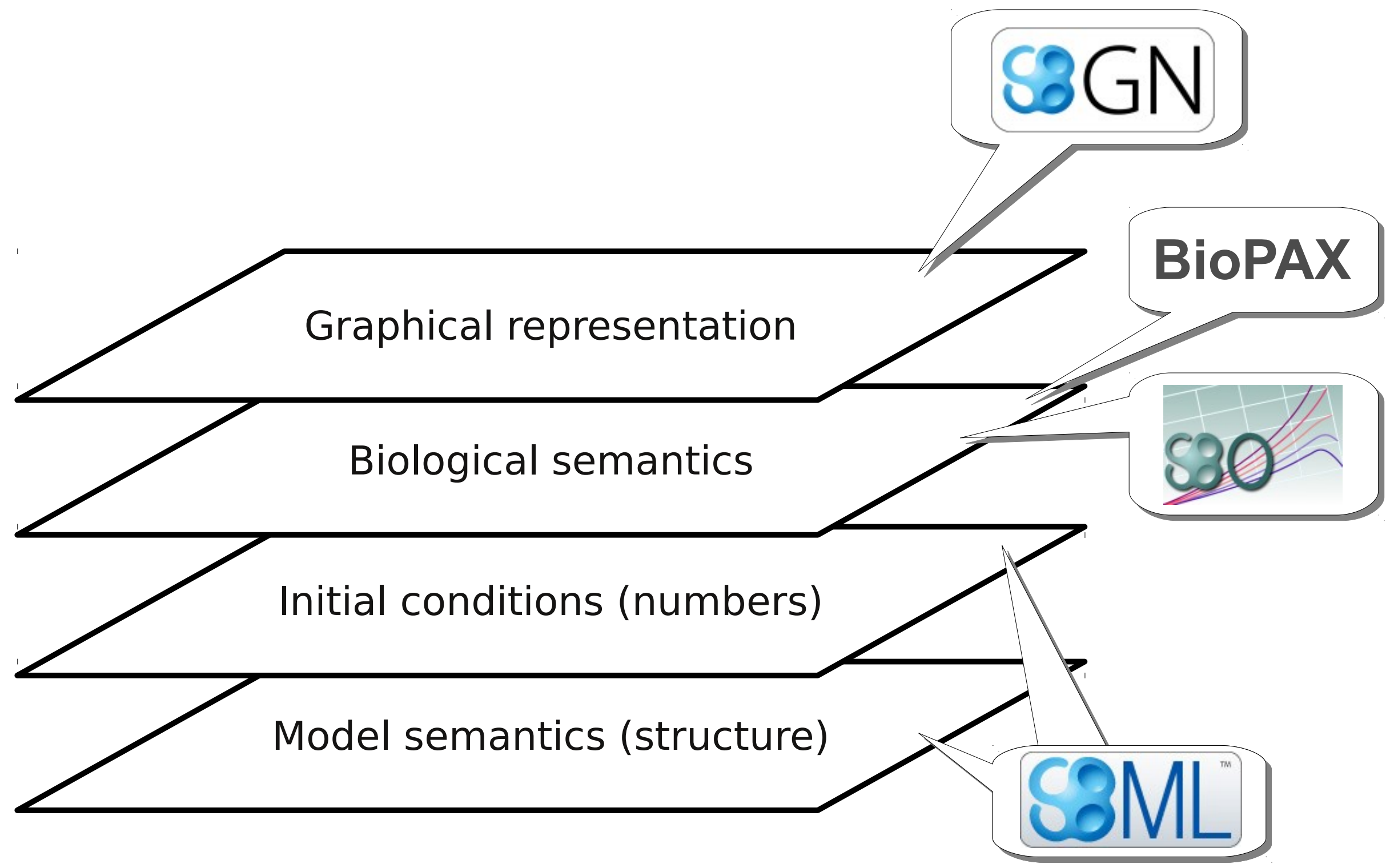




\section{Parallel and redundant efforts}

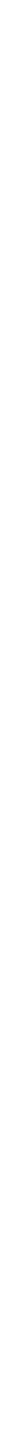


Multi-scale/approach representation using adapters (my opinion, not part of the vision ...)

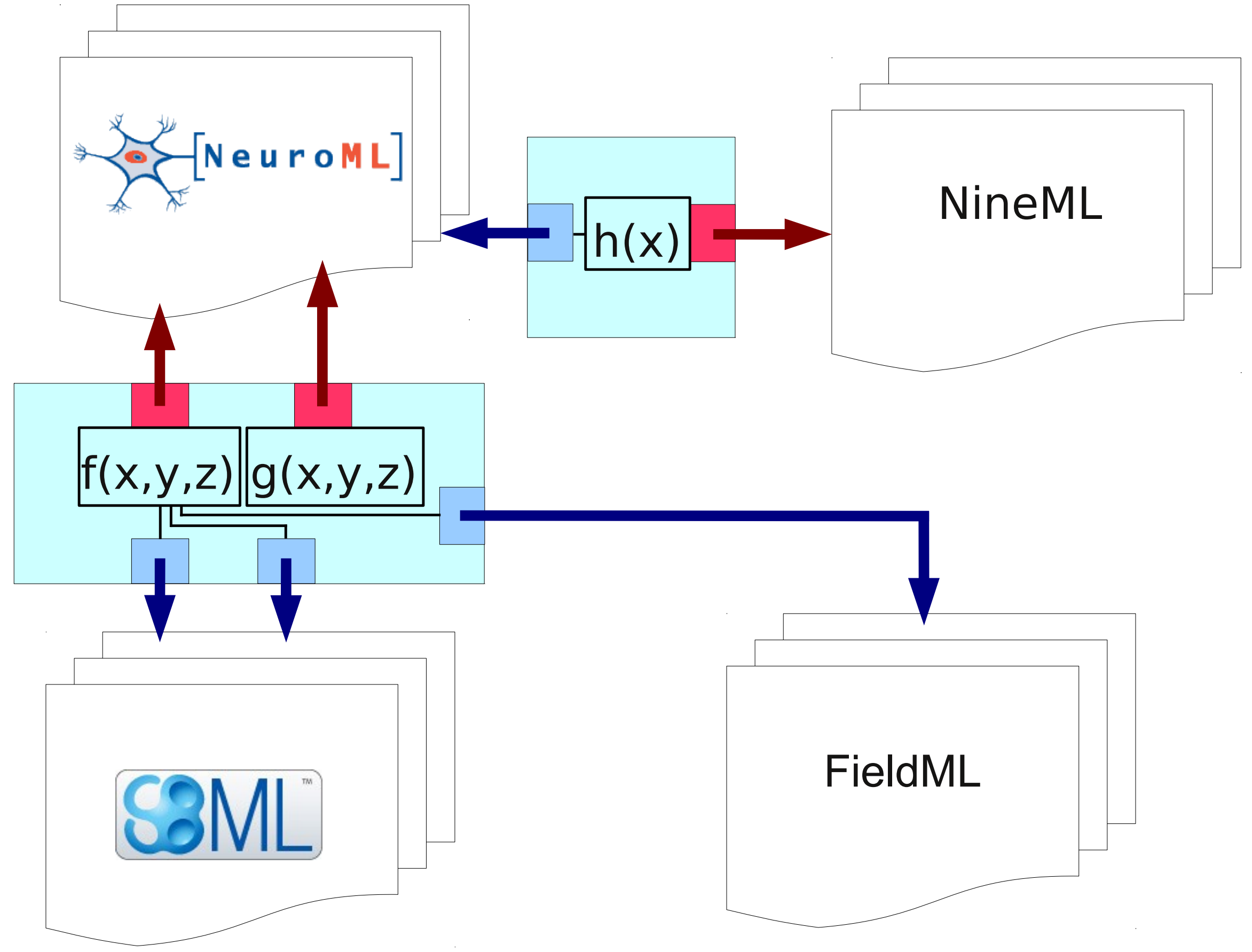




\section{Standards interoperability along the 3 dimensions}

- SBML to BioPAX: conversion using metadata (MIRIAM annotations and SBO terms), e.g.

- mapping between Species and PhysicalEntity

- mapping between Reactions and Physicallnteraction

- Conversion of SBML or BioPAX descriptions to SBGN map

- Usage of SBML descriptions (or CellML or VCML) in SED-ML: Identification of variables using XPath

- Descriptions using SBML and NeuroML: Interface based on XPath 


\section{Threats to the whole enterprise}

- Current efforts are very dependent on key people coordinating maintenance and development. Their disengagement would mean stalling or even discontinuation.

- Current funding structure is fragile. Many different grants, sometimes only supporting meetings (SBGN), none of them infrastructure rolling funding, often tied to individuals.

- Current efforts are not immune against intellectual property claims that would hinder the use of the standards

- Existing standards are developed with very different approaches, quality checks, and are based on completely different assumptions

- APIs needs industry-grade support, incompatible with standard academic usages and possibilities 


\section{Requirements for a overarching standardisation structure}

- What?

- Set of interoperable description languages

- Cover all aspects of modelling and simulation, all types of descriptions / views of the real

- Role of community-maintained ontologies.

- How?

- Independence towards Institutions, funders and individuals

- Role of European Research Infrastructures? (ELIXIR, ISBE)

- Who?

- Communities developing their standards: Systems Biology, Physiology (VPH), Neuroscience (INCF), Drug discovery (DDMoRe), Clinical data (CDISC) ...

- Other players in knowledge-representation: W3C ...

- Academic and corporate users: Modeling platforms (MatWorks ...), Pharma (Pistoia alliance) ... 
- What?

\section{Requirements for a overarching standardisation structure}

- Set of interoperable description languages

- Cover all aspects of modelling and simulation, all types of descriptions / views of the real

- Role of community-maintained ontologies.

- How?

- Independence towards Institutions, funders and individuals

- Role of European Research Infrastructures? (ELIXIR, ISBE)

- Who?

- Communities developing their standards: Systems Biology, Physiology (VPH), Neuroscience (INCF), Drug discovery (DDMoRe), Clinical data (CDISC) ...

- Other players in knowledge-representation: W3C ...

- Academic and corporate users: Modeling platforms (MatWorks ...), Pharma (Pistoia alliance) ...

\section{COmputational Modeling in Blology NEtwork} (COMBINE) forthcoming: http://co.mbine.org 


\section{ABOUT W3C}

The World Wide Web Consortium (W3C) is an intemational community where Memberorganizations. a full-time staff. and the public work together to develop Web standards. Led by Web inventor Tim Bemers-Lee and CEO Jeff rey Jaffe. W3C's mission is to lead the Web to its full potential. Contact W3C for more information.

\section{W3C Mission 目 \\ . Principles, vision, ...}

\section{Facts About W3C 直}

- People, organization, revenues, process, patent policy, history, ...

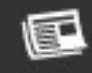

\section{Press and Analysts 国}

- Press releases, requests for photos and interviews, ...

\section{Os Donations}

- Support for W3C operations, validator service, ...

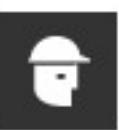

\section{Jobs and Fellowships 目}

- Employment opportunities, fellows, ...

\section{Questions About W3C or the Web?}

Please consult the Help and FAQ for answers to questions such as:

What does $\mathrm{W} 3 \mathrm{C}$ do?

How is W3C funded?

Is W $3 \mathrm{C}$ sending me spam?

What is the difference between the Web and the Internet?
QUICK LINKS

Contact

Staff

Help and FAQ

Systems Status (outages) 


\section{W3C 目}

$\check{\check{c}}$

\section{కStandards}

- Participate

$$
\Phi
$$$$
\text { OMembership }
$$$$
\text { -About W3C }
$$$$
\text { ชิ่ }
$$

Oึ.Member Home

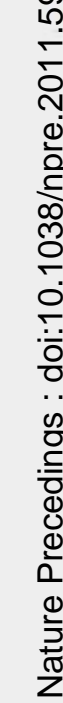

\section{ABOUT W3C}

The World Wide Web Consortium (W3C) is an intemational community where Memberorganizations, a full-time staff. and the public work together to devebp Web standards. Led by Web inventor Tim Bemers-Lee and CEO Jeff rey Jaffe. W3C's mission is to lead the Web to its full potential. Contact W3C for more information.

\section{QUICK LINKS}

Contact

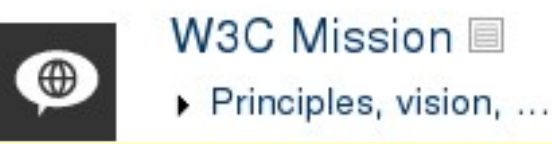

Staff

Help and FAQ

\section{A "WorldWide Web consortium" for the modeling in life-sciences}

\section{Donations 目}

- Support for W3C operations, validator service, ...

Jobs and Fellowships 目

- Employment opportunities, fellows, ...

Questions About W3C or the Web?

Please consult the Help and FAQ for answers to questions such as:

What does $\mathrm{W} 3 \mathrm{C}$ do?

How is W $3 \mathrm{C}$ funded?

Is W3C sending me spam?

What is the difference between the Web and the Internet? 
